Click here to download Manuscript: UNC13A in spanish ALS text+Tables 20150629 REVISED.doc

Click here to view linked References

\title{
UNC13A confers risk for Sporadic ALS and influences survival in a Spanish cohort
}

\author{
Authors: \\ Jose M. Vidal-Taboada ${ }^{\mathrm{a}}$, Alan Lopez-Lopez ${ }^{\mathrm{a}}$, Maria Salvado ${ }^{\mathrm{b}}$, Laura Lorenzo ${ }^{\mathrm{b}}$, Cecilia Garcia ${ }^{\mathrm{b}}$, Nicole \\ Mahy $^{\mathrm{a}}$, Manuel J. Rodríguez ${ }^{\mathrm{a}}$, Josep Gamez
}

\section{Author Affiliations:}

${ }^{a}$ Biochemistry and Molecular Biology Unit. Dept. of Physiological Sciences I. Faculty of Medicine IDIBAPS. Universitat de Barcelona. Barcelona. Spain. Centro de Investigación Biomédica en Red sobre Enfermedades Neurodegenerativas (CIBERNED, ISCIII), Barcelona, Spain.

${ }^{\mathrm{b}}$ ALS Unit. Neurology Department. Hospital Universitari Vall d'Hebron - VHIR. Autonomous University of Barcelona. FEDER. Barcelona, Spain.

\section{Corresponding author and reprint requests:}

Josep Gamez, MD, PhD.

ALS Unit. Neurology Department. Hospital Universitari Vall d'Hebron, VHIR.

Autonomous University of Barcelona.

Passeig Vall d'Hebron 119. 08035 Barcelona, Spain.

e-mail: josepgamez.bcn@gmail.com

Tel: + 34932746000

Fax: +34932110912

Correspondence may also be addressed to: Jose Manuel Vidal-Taboada, PhD.

Biochemistry and Molecular Biology Unit, Dept. of Physiological Sciences I, Faculty of Medicine, University of Barcelona.

Casanova 143. 08036 Barcelona. Spain.

e-mail: josevidal@ub.edu

Phone: +34 934020294. Fax: +34 934035882 .

Word Count: 2872; Figures: 1, Tables 5, and 46 references.

Running title: UNC13A in Spanish sALS

Keywords: Amyotrophic Lateral Sclerosis, ALS, UNC13A, rs12608932, susceptibility, modifying gene.

Acknowledgements: The authors are indebted to the patients and their relatives for their cooperation. The authors are grateful to the Spanish National DNA Bank (Salamanca, Spain) for supplying control samples and Dr. Josep Saura and Marta Pulido for their results of Munc13-1 gene expression in mice.

JG is the recipient of a grant from the Spanish Fondo de Investigaciones Sanitarias (PI10-01070 and FIS PI13-01272-FEDER), and an Interlaken Research Awards Program. This work was supported by grant IPT-2012-0614-010000 from the Ministerio de Economia y Competitividad and by grant 2014SGR1115 from the Generalitat de Catalunya to MJR, Spain. 


\section{ABSTRACT}

Objective. To investigate the association of functional variants of the human UNC13A gene with the risk of ALS, survival and the disease progression rate in a Spanish ALS cohort.

Methods. 136 sporadic ALS (sALS) patients and 487 healthy controls were genotyped for the UNC13A rs12608932 variant. Clinical characterization of ALS patients included gender, age at first symptom, initial topography, disease progression rate, and survival. Genetic association was analyzed under five inheritance models.

Results. The sALS patients with the $\mathrm{rs} 12608932^{\mathrm{CC}}$ genotype had an increased risk of ALS under a recessive genetic model $(\mathrm{OR}=2.16 ; 95 \% \mathrm{CI}[1.23,3.8], \mathrm{p}=0.009$; corrected $\mathrm{p}=0.028)$. Genotypes with a $\mathrm{C}$ allele are also associated with increased risk $(\mathrm{OR}=1.47 ; 95 \%$ CI $[1.11,1.95] ; \mathrm{p}=0.008$; corrected $\mathrm{p}$ $=0.023$ ) under an additive model. sALS patients with a $\mathrm{C} / \mathrm{C}$ genotype had a shorter survival than patients with $\mathrm{A} / \mathrm{A}$ and $\mathrm{A} / \mathrm{C}$ genotypes $(\mathrm{HR}=1.44 ;(95 \% \mathrm{CI}[1.11,1.873] ; \mathrm{p}=0.007)$ under a recessive model. In an overdominant model, heterozygous patients had a longer survival than homozygous patients $(\mathrm{HR}=0.36$ (95\% CI [0.22, 0.59]; $\mathrm{p}=0.001)$. The rs12608932 genotypes modify the progression of symptoms measured using the ALSFRS-R. No association with age of onset, initial topography or rate of decline in FVC was found.

Conclusion. Our results show that rs12608932 is a risk factor for ALS in the Spanish population, and replicate the findings described in other populations. The rs12608932 is a modifying factor for survival and disease progression rate in our series. Our results also corroborated that it did not influence the age of onset. 


\section{INTRODUCTION}

Amyotrophic lateral sclerosis (ALS) is the most frequent degenerative disorder affecting motor neurons in adults. Phenotypic heterogeneity is a characteristic feature of the disease, with different survival times, ages of onset, types of onset, gender predominance, degrees of upper and lower motor neuron signs, and rates of progression. This heterogeneity is relevant in clinical trials, as a significant number of atypical phenotypes may lead to bias in the results. Many authors are undecided as to whether ALS should be considered a single disease or a syndrome $[1,2]$.

Like most neurodegenerative disorders, environmental and genetic factors have been described as determining the broad variability of the ALS phenotype. Over the last two decades, ALS research has focused on the search for genetic factors which would account for this phenotypic heterogeneity. New gene screening methodologies, especially genome-wide association studies (GWAS), genomic structural variation studies, and whole exome sequencing (WES), have led to the identification of 32 causing genes and 8 different genetic loci with dominant, recessive and X-linked patterns of inheritance for familial ALS. An increasing number of susceptibility and modifier loci have also been suggested for sporadic (sALS) and familial ALS cases. Gene-gene and gene-environment interactions also seem to play an important role in the appearance and phenotype of the disease [3-6].

Ascertaining genetic susceptibility and determining gene-environment interactions for ALS susceptibility loci that contribute to sALS can improve our understanding of the underlying pathogenic mechanisms of ALS. Genome-wide association studies (GWAS) have provided evidence that various modifier loci and associated genes are related to complex diseases including sALS $[5,6]$.

UNC13A gene has been shown to be a powerful modifying gene of survival and progression in sALS in Western populations, but not in Asian groups [7-16]. In order to confirm whether this is indeed the case, larger independent studies of other populations that replicate these findings are needed to establish their definite role in ALS. This gene has never been investigated in the Spanish ALS population. In this study, we examine whether UNC13A has disease-modifying effects in a series of 136 Spanish sporadic ALS patients. 


\section{MATERIAL AND METHODS}

\section{Study population and clinical data}

A cohort of 136 sALS patients meeting the revised El Escorial criteria for Clinically Definite ALS, Clinically Probable ALS, or Clinically Probable ALS - Laboratory-supported was included in this study [17]. A control group of 750 non-affected and non-related subjects was recruited from the Spanish National DNA Bank (Salamanca, Spain). A subset of 487 controls was randomly selected to assess the risk of disease, matching for age and sex. The control and sALS patients were Spanish citizens of European origin.

The patients were clinically characterized, monitored and received quarterly follow-up in the Hospital Universitari Vall d'Hebron ALS Unit. Gender, age at onset, initial topography and survival time (defined as the time between the onset of clinical symptoms and the date of death, or the date of tracheostomy ventilation, or the date when non-invasive ventilation of more than $23 \mathrm{~h}$ /day was required) were ascertained for each patient using the homogeneous criteria of a unique observer (JG) (see Table 1 for a detailed demographic description). All the patients had previously been screened for C9orf72 expansions and SOD1 mutations [18, 19] which are the most common genetic defects in sALS patients in our population.

The patients were classified as (i) bulbar, spinal or respiratory onset, and (ii) according to the rate of progression. The mean slopes for ALSFRS-R decline and for FVC decline reported in the historical control groups in the minocycline in ALS trial (MINO), used in a lithium trial, were applied as a tool for classifying the patients' rate of progression in our ALS cohort [20, 21]. The ALSFRS-R is the most commonly used outcome marker of disease progression in clinical practice and research, and evaluates symptoms related to bulbar, limb, and respiratory function. The rate of change in ALSFRS-R provides useful guidance on patients' progression and may predict survival and indirectly measure the disease's progression from a statistical point of view [22-24]. Distribution in tertiles was used to classify patients in three subgroups: fast progression (subgroup P1, first tertile for ALSFRS-R and FVC values); normal progression (subgroup P2, second tertile for ALSFRS-R and FVC values); and slow progression (subgroup P3, third tertile for ALSFRS-R and FVC values).

\section{DNA purification and Genotyping}

Genomic DNA samples were extracted from whole blood samples of patients using the QIAamp DNA Mini Kit (QIAGEN, USA) according to the manufacturer's instructions.

The UNC13A rs12608932 variant was genotyped using the KASPar SNP Genotyping System (LGC Genomics, UK) according to the provider's standard procedures using the following primer set (UNC13A_A: 5'ATCCA TCCAC CCATC AATTT ATCCAA3'; UNC13A_C: 5'CCATC CACCC ATCAA TTTAT CCAC3'; and UNC13A_rev: 5'GAGTG GCTGG TGGAC AGACG AA3'. Fluorescence was measured at $25^{\circ} \mathrm{C}$ in a 7300 real time PCR System (Applied Bioscience, USA). Genotype calling was carried out using 7300 system SDS software v1.4 (Applied Bioscience, USA) and Klustercaller software (KBioscience, UK). 


\section{Statistical Design, Analysis and Power}

The study design was based on a pragmatic, case-control, retrospective clinical study. The samples analyzed were 136 sALS patients and 487 controls (three controls per case). UNC13A rs12608932 genotypes were used as predictors of the progression rate of the symptoms, the survival time, the risk of suffering ALS and the age at onset.

The odds ratio (OR) and the 95\% Confidence Interval (95\% CI) were computed using generalized linear models (for either quantitative or binary traits), as implemented in the SNPassoc package from R Software [25]. Analyses were performed using five different inheritance models: additive, codominant, dominant, overdominant and recessive. The Hardy-Weinberg Equilibrium (HWE) was calculated using Fisher's exact test implemented in the SNPassoc package. Ordinal logistic regression was carried out using SPSS software (IBM, Spain). Analyses were performed adjusted by sex, age at onset and topographic clinical onset, based on previous studies by other groups (see table 2) [12, 14]. p-values were corrected by a factor of 3 to correct for multiple comparisons using 5 different genetic models [25-27]. Using this criterion, the uncorrected level for statistical significance was established at $\mathrm{p}<0.017$. The uncorrected and corrected p-values are shown.

Survival analysis was performed using Kaplan-Meier curves and COX multivariable regression (SPSS software), including all the dead patients and those alive and receiving either non-invasive ventilation for more than 23 hours a day or ventilation by tracheostomy.

Sample size and statistical power were calculated using Quanto software [28]. This study has a prior statistical power of $80 \%($ alpha $=5 \%$ ) for detecting a difference of 15 months in survival between groups of patients (main population survival $=49.27 \pm 41.6$ months, minor allele frequency $=0.307$ ), and a beta of $98 \%$ (alpha $=5 \%$ ) for detecting a difference of $>21$ months. For the risk of suffering ALS, this study has a power of $80 \%$ (alpha $=5 \%$ ) for detecting an OR $>1.5$ between cases and controls. 


\section{RESULTS}

We obtained the genotype of UNC13A rs12608932 polymorphism in 136 sALS patients and 487 controls of the Spanish population. The genotyping results indicated that these genotypes were in HWE (p = $0.5104)$ in cases $(\mathrm{p}=0.2788)$ and controls $(\mathrm{p}=1.0)$

Association analysis of this polymorphism with the risk of suffering ALS under different models of inheritance has shown that the SNP rs12608932 is a risk marker for ALS in our Spanish ALS series. Patients with the CC genotype had an increased risk of suffering from ALS with an OR of $2.16(95 \% \mathrm{CI}$ $[1.23,3.8])$, a result that was statistically significant $(\mathrm{p}=0.009$; corrected $\mathrm{p}$-value $=0.028)$ under a recessive model (table 2 and 3). The genotypes with the $\mathrm{C}$ allele were also associated with an increased disease risk under an additive model $(\mathrm{OR}=1.47 ; 95 \% \mathrm{CI}[1.11,1.95] ; \mathrm{p}=0.008$; corrected $\mathrm{p}$-value $=0.023)$. The same risk was observed for sALS patients with spinal topographic onset under recessive (OR $=1.91$; $95 \%$ CI $[1.7,3.43] ; \mathrm{p}=0.035)$ and additive $(\mathrm{OR}=1.40 ; 95 \% \mathrm{CI}[1.05,1.86] ; \mathrm{p}=0.024)$ models.

As regards the survival of ALS patients, we grouped sALS patients under different genetic models and performed a Kaplan Meyer Survival curve and Cox regression analyses. Under a recessive model, the results showed statistical differences between patients with $U N C 13 A \mathrm{~A} / \mathrm{A}$ and $\mathrm{A} / \mathrm{C}$ genotypes (median=57.0 months, 95\% CI $[48.9,65.1]$ ) and a C/C genotype (median=24.0 months, 95\% CI [21.4, 26.6]) with a long $\operatorname{Rank}=0.011$ and $\mathrm{HR}=1.44$ (95\% CI [1.11, 1.873]; p-value=0.007; Table 4; Figure 1A). This result indicated that a CC genotype would be a risk factor for shorter survival. Under an overdominant model, there are also statistical differences between patients with a $U N C 13 \mathrm{~A} \mathrm{~A} / \mathrm{C}$ (median=90.0 months, 95\% CI [43.1, 136.9]) and A/A genotype or C/C genotypes (median=39.0 months, 95\% CI [16.1, 61.9]) with a long Rank=0.001 and HR=0.36 (95\% CI [0.22, 0.59]; p-value=0.001; Table 4; Figure 1B). The dominant model also showed statistical differences (Table 4). Under this model, AC genotype would be a genetic factor for longer survival.

As regards the progression of ALS symptoms: the ALSFRS-R scores of patients with A/C $(2.562 \pm 0.149)$ and $\mathrm{C} / \mathrm{C}(2.923 \pm 0.143)$ genotypes were lower than those for wild-type genotypes $(3.109 \pm 0.118)$. Under a dominant model, the difference $(2.562 \pm 0.149$ vs $3.056 \pm 0.094)$ was statistically significant (diff= $0.431 ; 95 \%$ CI [-0.747, -0.115$] ; \mathrm{p}=0.008$; corrected $\mathrm{p}$-value $=0.024)$. We also detected differences under an overdominant model (diff $=-0.460 ; 95 \%$ CI $[-0.770,-0.149] ; p=0.004$; corrected $p$-value $=0.012$; table 5). No statistical differences were observed on the FVC between genotypes under the different genetic models (table 2).

Measuring the ALS symptom progression ranked the patients by ALSFRS-R and FVC scores by tertiles: we found no associations under any genetic models.

We also observed no statistical association between the genetic marker UNC13A rs12608932 and the age of onset, gender or the topographic onset in our series of Spanish ALS patients (Table 2). 


\section{DISCUSSION}

Here we report the association analysis of the SNP rs12608932 in the UNC13A gene as a disease risk and modifying genetic factor in a cohort of Spanish sALS patients. Our results showed that this variant is a risk factor for the development of ALS in our sALS population. Furthermore, our results indicated that the UNC13A gene could be a modifying factor for the progression of the disease's symptoms and survival time. We found no evidence of rs12608932 affecting the age at onset of the disease or its topographic onset.

This is the first time that the genetic analysis of rs12608932 has been performed in Spanish ALS cases. Our disease risk results are consistent with the previous results describing UNC13A as a risk factor for ALS in North American, Dutch and Belgian ALS populations [7, 8, 12, 15]. All these results indicate that this marker is a genetic risk factor for suffering from sporadic ALS in most of the European populations. However, this risk has not been found in other populations from Italy, China and Japan $[11,14,16]$.

Our results indicate that patients with the UNC13A rs12608932 C/C genotype have shorter survival times (33 months) than $\mathrm{A} / \mathrm{A}$ or $\mathrm{A} / \mathrm{C}$ patients under a recessive model. This effect is identical to that reported for the Italian [14] and Dutch populations [12]. In the Spanish ALS population, the CC genotype would be a risk factor for survival. However, an alternative aggrupation of patients under an overdominant genetic model showed that the patients with A/C genotype have a longer survival than patients with AA or CC. Consequently, the heterozygous genotype would be a protective factor. This is the first reported analysis of the overdominant model of the UNC13A rs12608932 polymorphism in association with ALS survival. This is also the first time that the analysis of rs12608932 has been performed using five genetic models, including co-dominant and overdominant models. Our results using these five models introduce the hypothesis of the heterozygote's advantage role in the resulting phenotype of ALS patients.

To the best of our knowledge, this is the first time the UNC13A rs12608932 variant has been associated with the disease's progression of symptoms, as measured by the ALSFRS-R scale. Our results indicate that the genotypes containing the $\mathrm{C}$ allele are risk factors for decline in the ALSFRS-R score. This enables us to propose that the UNC13A rs12608932 could be a new modifying factor for disease progression.

Finally, although the UNC13A rs12608932 variant has been proposed as a modifying gene for the age of onset [29] in different populations from USA and Europe, we did not observe this association in the Spanish series analyzed in our study.

The role of UNC13A in ALS pathogenesis has been proposed due to its involvement in the release of neurotransmitters such as glutamate by neuronal presynaptic vesicles [7]. Mice lacking UNC13A suffer from disrupted glutamatergic neurotransmission due to arrested synaptic vesicle maturation [30]. It has been argued that the UNC13A gene could be involved in glutamate-mediated excitotoxicity in ALS, with evidence suggesting glutamatergic excitotoxicity as a significant mechanism for motor neuron death in ALS [7, 31]. A link between neuroinflammation and excitotoxicity has been proposed in the etiopathogenesis of ALS [32-34]. Neuroinflammation is one of the pathological hallmarks of ALS [4]. Microglia cells have a major role in neuroinflammation and their activation and crosstalk with immune cells appear to play a significant role in neuronal death in in vivo and in vitro studies [35-37]. In ALS, 
microglial activation correlates with disease progression and symptoms, and might therefore modify the outcome of this devastating disease [22, 38-41]. A GEO dataset search indicated that UNC13A gene is expressed in human microglia $[42,43]$. The mouse ortholog of human UNC13A, the Munc13-1 gene, is expressed in mouse microglia [Josep Saura, personal communication] and in peripheral mouse macrophages [44]. In macrophages, Munc13-1 has been proposed as a membrane fusion regulating protein that interacts with Rab37. In activated macrophages, both proteins colocalized in vesicles containing TNF- $\alpha$ and knockdown of Munc13-1 by siRNA significantly decreased TNF- $\alpha$ secretion. These data indicate that Munc13-1 (UNC13A) is related to the control of TNF-a secretion in activated macrophages and the inflammatory process [44]. No data about this effect related to microglia has been published to date.

Our study has some specific strong points. It is the only one that analyzes the association using the five different inheritance models: additive, codominant, dominant, overdominant and recessive. It is the first to use the mean estimated slope for ALSRFS-R and FVC decline observed in the control patients in the MINO trial to measure functional and respiratory deterioration. In addition, there is homogeneity in the criteria for evaluating the clinical variables, because the clinical data were collected by a unique observer in a unique center. This study is also well powered (beta $>95 \%$, alpha $=5 \%$ ) for detecting changes in the survival in sALS patients with different UNC13A genotypes. However, these findings must be interpreted with caution due to the small number of patients (the major limitation of the study). Although the cohort is relatively small - consistent with the incidence in Catalonia being among the lowest rates in Europe $[18,45]$ - this study is sufficiently well powered (beta $>95 \%$, alpha $=5 \%$ ) to replicate the disease risk association reported in different Caucasian populations and to detect changes in the survival of sALS patients with different UNC13A genotypes. It also fails to take into consideration dietary factors, lifestyle, physical activity, occupational and other environmental risk factors which were found to be significant in other populations [46].

The identification of biomarkers associated with different rates of progression and survival time could provide new insights into the pathophysiological determinants of disease progression in ALS. Our results show that rs 12608932 is a risk factor for ALS in the Spanish population, and replicate the findings previously described in other western populations. The rs12608932 variant is a modifying factor for survival and disease progression in our series. These results suggest that UNC13A could be an interesting potential target for developing strategies for controlling neurodegeneration in ALS. 


\section{ETHICAL STATEMENT}

This genetic study was approved by the local IRBs at the Vall d'Hebron Research Institute and the Spanish National DNA Bank. The study has been conducted according to the principles expressed in the Declaration of Helsinki. All patients gave their informed written consent to participation in the study prior to their inclusion in the study, and a blood sample for genetic analysis was obtained from all of them.

\section{CONFLICT OF INTEREST}

The authors declare that they have no conflict of interest. 


\section{REFERENCES}

1. Chiò A, Calvo A, Moglia C, et al. (2011) Phenotypic heterogeneity of amyotrophic lateral sclerosis: a population based study. J Neurol Neurosurg Psychiatry 82:740-6. doi: 10.1136/jnnp.2010.235952

2. Van den Berg LH (2011) ALS: disease or syndrome? J Neurol Neurosurg Psychiatry 82:711. doi: 10.1136/jnnp.2011.241513

3. Andersen PM, Al-Chalabi A (2011) Clinical genetics of amyotrophic lateral sclerosis: what do we really know? Nat Rev Neurol 7:603-15. doi: 10.1038/nrneurol.2011.150

4. Ince PG, Highley JR, Kirby J, et al. (2011) Molecular pathology and genetic advances in amyotrophic lateral sclerosis: an emerging molecular pathway and the significance of glial pathology. Acta Neuropathol 122:657-71. doi: 10.1007/s00401-011-0913-0

5. Al-Chalabi A, Hardiman O (2013) The epidemiology of ALS: a conspiracy of genes, environment and time. Nat Rev Neurol 9:617-28. doi: 10.1038/nrneurol.2013.203

6. Renton AE, Chiò A, Traynor BJ (2014) State of play in amyotrophic lateral sclerosis genetics. Nat Neurosci 17:17-23. doi: 10.1038/nn.3584

7. Van Es MA, Veldink JH, Saris CGJ, et al. (2009) Genome-wide association study identifies $19 \mathrm{p} 13.3$ (UNC13A) and 9p21.2 as susceptibility loci for sporadic amyotrophic lateral sclerosis. Nat Genet 41:1083-7. doi: 10.1038/ng.442

8. Shatunov A, Mok K, Newhouse S, et al. (2010) Chromosome 9p21 in sporadic amyotrophic lateral sclerosis in the UK and seven other countries: a genome-wide association study. Lancet Neurol 9:986-94. doi: 10.1016/S1474-4422(10)70197-6

9. Daoud H, Belzil V, Desjarlais A, et al. (2010) Analysis of the UNC13A gene as a risk factor for sporadic amyotrophic lateral sclerosis. Arch Neurol 67:516-7. doi: 10.1001/archneurol.2010.46

10. Laaksovirta H, Peuralinna T, Schymick JC, et al. (2010) Chromosome 9p21 in amyotrophic lateral sclerosis in Finland: a genome-wide association study. Lancet Neurol 9:978-85. doi: $10.1016 /$ S1474-4422(10)70184-8

11. Iida A, Takahashi A, Deng M, et al. (2011) Replication analysis of SNPs on 9p21.2 and 19p13.3 with amyotrophic lateral sclerosis in East Asians. Neurobiol Aging 32:757.e13-4. doi: 10.1016/j.neurobiolaging.2010.12.011

12. Diekstra FP, van Vught PWJ, van Rheenen W, et al. (2012) UNC13A is a modifier of survival in amyotrophic lateral sclerosis. Neurobiol Aging 33:630.e3-8. doi: 10.1016/j.neurobiolaging.2011.10.029

13. Kwee LC, Liu Y, Haynes C, et al. (2012) A high-density genome-wide association screen of sporadic ALS in US veterans. PLoS One 7:e32768. doi: 10.1371/journal.pone.0032768

14. Chiò A, Mora G, Restagno G, et al. (2013) UNC13A influences survival in Italian amyotrophic lateral sclerosis patients: a population-based study. Neurobiol Aging 34:357.e1-5. doi: 10.1016/j.neurobiolaging.2012.07.016

15. Fogh I, Ratti A, Gellera C, et al. (2014) A genome-wide association meta-analysis identifies a novel locus at 17q11.2 associated with sporadic amyotrophic lateral sclerosis. Hum Mol Genet 23:2220-31. doi: $10.1093 / \mathrm{hmg} / \mathrm{ddt} 587$ 
16. Chen X, Huang R, Chen Y, et al. (2014) Association analysis of four candidate genetic variants with sporadic amyotrophic lateral sclerosis in a Chinese population. Neurol Sci 35:1089-95. doi: $10.1007 / \mathrm{s} 10072-014-1656-1$

17. Forbes RB, Colville S, Swingler RJ (2001) Are the El Escorial and Revised El Escorial criteria for ALS reproducible? A study of inter-observer agreement. Amyotroph Lateral Scler Other Motor Neuron Disord 2:135-8.

18. Gamez J, Corbera-Bellalta M, Nogales G, et al. (2006) Mutational analysis of the $\mathrm{Cu} / \mathrm{Zn}$ superoxide dismutase gene in a Catalan ALS population: should all sporadic ALS cases also be screened for SOD1? J Neurol Sci. 247:21-8.

19. Syriani E, Salvans C, Salvadó M, Morales M, Lorenzo L, Cazorla S, Gamez J. (2014) PFN1 mutations are also rare in the Catalan population with amyotrophic lateral sclerosis. J Neurol. 261:2387-92. doi: 10.1007/s00415-014-7501-x.

20. Gordon PH, Moore DH, Miller RG, et al. (2007) Efficacy of minocycline in patients with amyotrophic lateral sclerosis: a phase III randomised trial. Lancet Neurol 6:1045-53. doi: 10.1016/S1474-4422(07)70270-3

21. Miller RG, Moore DH, Forshew DA, et al. (2011) Phase II screening trial of lithium carbonate in amyotrophic lateral sclerosis: examining a more efficient trial design. Neurology 77:973-9. doi: 10.1212/WNL.0b013e31822dc7a5.

22. Simon NG, Turner MR, Vucic S, Al-Chalabi A, Shefner J, Lomen-Hoerth C, Kiernan MC. (2014) Quantifying disease progression in amyotrophic lateral sclerosis. Ann Neurol. 76:643-57. doi: 10.1002/ana.24273.

23. Creemers H, Grupstra H, Nollet F, van den Berg LH, Beelen A. (2015) Prognostic factors for the course of functional status of patients with ALS: a systematic review. J Neurol. 262:1407-23. doi: $10.1007 / \mathrm{s} 00415-014-7564-8$.

24. Elamin M, Bede P, Montuschi A, Pender N, Chio A, Hardiman O. (2015) Predicting prognosis in amyotrophic lateral sclerosis: a simple algorithm. J Neurol. 262:1447-54. doi: 10.1007/s00415015-7731-6.

25. Gonzalez JR, Armengol L, Sole X, et al. (2007) SNPassoc: an R package to perform whole genome association studies. Bioinformatics 23:654-655. doi: 10.1093/bioinformatics/btm025

26. Ballana E, Senserrich J, Pauls E, et al. (2010) ZNRD1 (zinc ribbon domain-containing 1) is a host cellular factor that influences HIV-1 replication and disease progression. Clin Infect Dis 50:102232. doi: $10.1086 / 651114$

27. Lopez-Lopez A, Gamez J, Syriani E, et al. (2014) CX3CR1 is a modifying gene of survival and progression in amyotrophic lateral sclerosis. PLoS One 9:e96528. doi: 10.1371/journal.pone.0096528

28. Gauderman WJ MJ (2006) QUANTO 1.1: A computer program for power and sample size calculations for genetic-epidemiology studies. http://hydra.usc.edu/gxe. Accessed 20 Mai 2015

29. Ahmeti KB, Ajroud-Driss S, Al-Chalabi A, et al. (2013) Age of onset of amyotrophic lateral sclerosis is modulated by a locus on 1p34.1. Neurobiol Aging 34:357.e7-19. doi: 10.1016/j.neurobiolaging.2012.07.017

30. Varoqueaux F, Sons MS, Plomp JJ, Brose N (2005) Aberrant morphology and residual transmitter release at the Munc13-deficient mouse neuromuscular synapse. Mol Cell Biol 25:5973-84. doi: 10.1128/MCB.25.14.5973-5984.2005 
31. Augustin I, Rosenmund C, Südhof TC, Brose N (1999) Munc13-1 is essential for fusion competence of glutamatergic synaptic vesicles. Nature 400:457-61. doi: 10.1038/22768

32. Olmos G, Lladó J (2014) Tumor necrosis factor alpha: a link between neuroinflammation and excitotoxicity. Mediators Inflamm 2014:861231. doi: 10.1155/2014/861231

33. Batlle M, Ferri L, Andrade C, et al. (2015) Astroglia-Microglia Cross Talk during Neurodegeneration in the Rat Hippocampus. Biomed Res Int 2015:102419. doi: $10.1155 / 2015 / 102419$

34. Espinosa-Parrilla JF, Martínez-Moreno M, Gasull X, et al. (2015) The L-type voltage-gated calcium channel modulates microglial pro-inflammatory activity. Mol Cell Neurosci 64:104-15. doi: $10.1016 /$ j.mcn.2014.12.004

35. Appel SH, Zhao W, Beers DR, Henkel JS (2011) The microglial-motoneuron dialogue in ALS. Acta Myol 30:4-8.

36. Beers DR, Henkel JS, Zhao W, et al. (2011) Endogenous regulatory T lymphocytes ameliorate amyotrophic lateral sclerosis in mice and correlate with disease progression in patients with amyotrophic lateral sclerosis. Brain 134:1293-314. doi: 10.1093/brain/awr074

37. McCombe PA, Henderson RD (2011) The Role of immune and inflammatory mechanisms in ALS. Curr Mol Med 11:246-54.

38. Boillée S, Yamanaka K, Lobsiger CS, et al. (2006) Onset and Progression in Inherited ALS Determined by Motor Neurons and Microglia. Science (80- ) 312:1389-1392. doi: $10.1126 /$ science. 1123511

39. Henkel JS, Beers DR, Zhao W, Appel SH (2009) Microglia in ALS: the good, the bad, and the resting. J Neuroimmune Pharmacol 4:389-98. doi: 10.1007/s11481-009-9171-5

40. Brettschneider J, Toledo JB, Van Deerlin VM, et al. (2012) Microglial activation correlates with disease progression and upper motor neuron clinical symptoms in amyotrophic lateral sclerosis. PLoS One 7:e39216. doi: 10.1371/journal.pone.0039216

41. Corcia P, Tauber C, Vercoullie J, et al. (2012) Molecular imaging of microglial activation in amyotrophic lateral sclerosis. PLoS One 7:e52941. doi: 10.1371/journal.pone.0052941

42. Rock RB, Hu S, Deshpande A, et al. (2005) Transcriptional response of human microglial cells to interferon-gamma. Genes Immun 6:712-9. doi: 10.1038/sj.gene.6364246

43. Yoshino T, Tabunoki H, Sugiyama S, et al. (2011) Non-phosphorylated FTY720 induces apoptosis of human microglia by activating SREBP2. Cell Mol Neurobiol 31:1009-20. doi: $10.1007 / \mathrm{s} 10571-011-9698-\mathrm{x}$

44. Mori R, Ikematsu K, Kitaguchi T, et al. (2011) Release of TNF- $\alpha$ from macrophages is mediated by small GTPase Rab37. Eur J Immunol 41:3230-9. doi: 10.1002/eji.201141640.

45. Pradas J, Puig T, Rojas-García R, Viguera ML, Gich I, Logroscino G; ALS-CAT Group. Amyotrophic lateral sclerosis in Catalonia: a population based study. Amyotroph Lateral Scler Frontotemporal Degener. 2013 May;14(4):278-83. doi: 10.3109/21678421.2012.749915.

46. Ingre C, Roos PM, Piehl F, et al. (2015) Risk factors for amyotrophic lateral sclerosis. Clin Epidemiol 7:181-93. doi: 10.2147/CLEP.S37505 


\section{Figure Captions}

Figure 1. Kaplan Meyer Survival Curves grouped by rs12608932_UNC13A genotypes under recessive (A) and overdominant (B) genetic models 
Agure 1
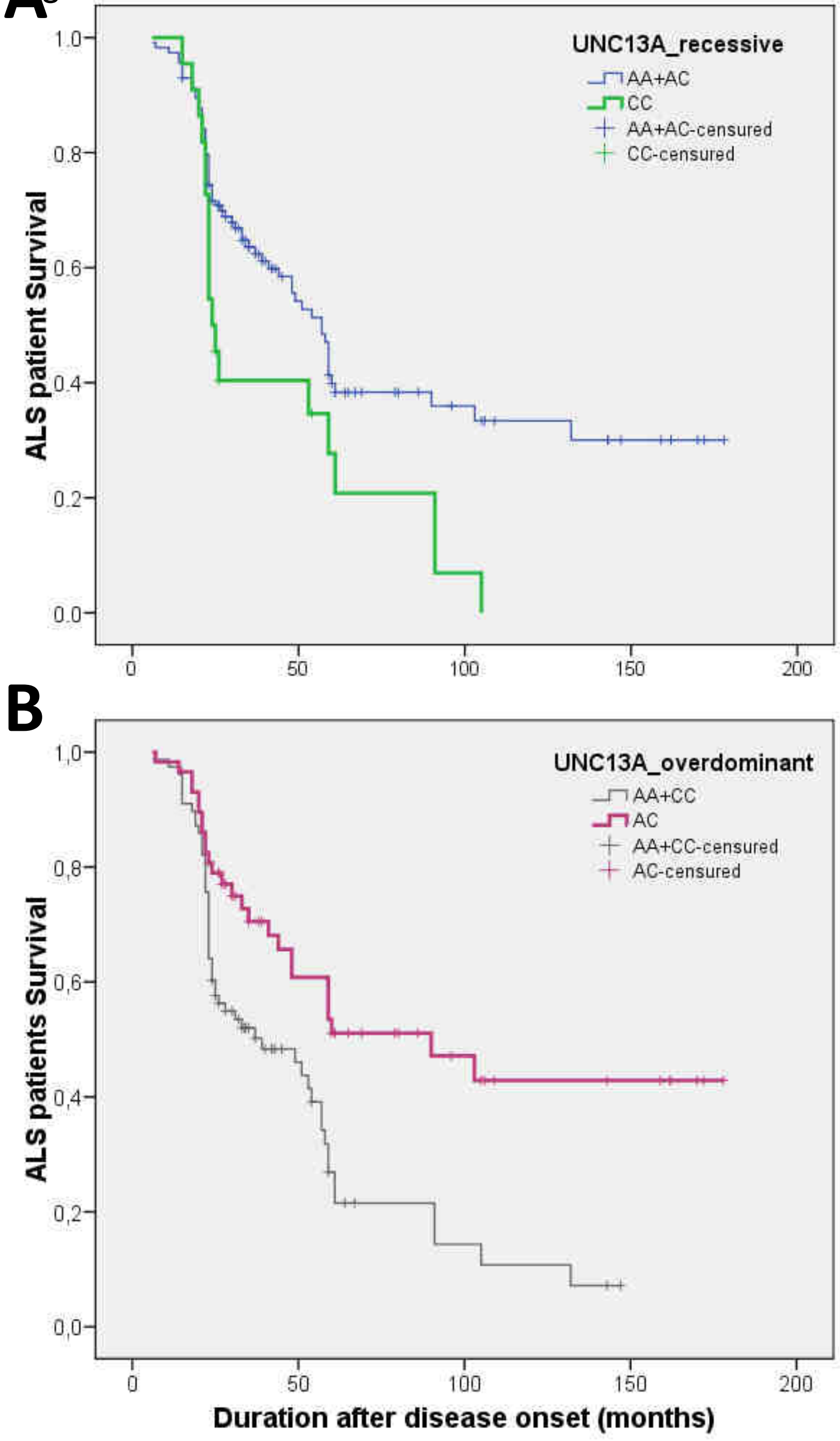
Table 1. Demography and clinical data

\begin{tabular}{lcc} 
& Control & sALS \\
\hline Subjects & 487 & 136 \\
Sex: female & 225 & 65 \\
$\quad$ male & 262 & 71 \\
Mean age (SD) & $57.81(14.10)$ & $61.24(12.92)$ \\
Mean age at onset (SD) & - & $57.24(13.79)$ \\
Median age at onset (range) & - & $58.5(22,85)$ \\
Spinal onset & - & 99 \\
Bulbar onset & - & 35 \\
Respiratory onset & - & 2 \\
\hline
\end{tabular}


Table 2. Association of p-values (non-corrected) of the rs 12608932 variant of the UNC13A gene for several phenotypes according to different inheritance models

\section{Genetic models}

\begin{tabular}{|c|c|c|c|c|c|c|}
\hline Phenotype & additive & dominant & recessive & co-domin. & over-domin. & adjusted by ${ }^{b}$ \\
\hline Disease Risk & 0.008 & 0.053 & 0.009 & 0.018 & 0.766 & $\mathrm{~S}+\mathrm{A}$ \\
\hline Age at onset & 0.461 & 0.662 & 0.400 & 0.696 & 0.843 & $\mathrm{~S}+\mathrm{T}$ \\
\hline Survival $^{\mathrm{a}}$ & 0.483 & 0.025 & 0.007 & 0.875 & 0.001 & $\mathrm{~S}+\mathrm{AO}+\mathrm{T}$ \\
\hline $\begin{array}{l}\text { Symptom } \\
\text { progression }\end{array}$ & 0.679 & 0.218 & 0.412 & 0.184 & 0.066 & $\mathrm{~S}+\mathrm{T}$ \\
\hline ALSFRS-R & 0.105 & 0.008 & 0.748 & 0.012 & 0.004 & $\mathrm{~S}+\mathrm{AO}+\mathrm{T}$ \\
\hline $\mathrm{FVC}$ & 0.295 & 0.491 & 0.269 & 0.520 & 0.882 & $\mathrm{~S}+\mathrm{AO}+\mathrm{T}$ \\
\hline Topography & 0.302 & 0.401 & 0.380 & 0.584 & 0.862 & $\mathrm{~S}+\mathrm{AO}$ \\
\hline
\end{tabular}

${ }^{\mathrm{a}}$ Cox Regression $\mathrm{p}$-value. ${ }^{\mathrm{b}} \mathrm{S}=\mathrm{sex}, \mathrm{A}=$ age, $\mathrm{AO}=$ age at onset, $\mathrm{T}=$ topography 
Table 3. Effect of the rs12608932_UNC13A variant on the risk of suffering ALS calculated for different genetic models (adjusted by sex and age)

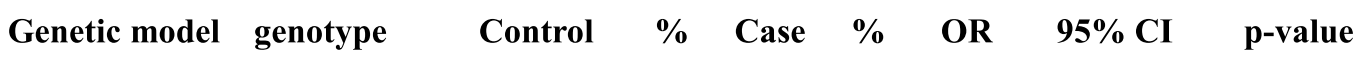

(n)

(n)

\begin{tabular}{|c|c|c|c|c|c|c|c|c|}
\hline Additive & $0,1,2^{\mathrm{a}}$ & 487 & 78.2 & 136 & 21.8 & 1.47 & $1.11,1.95$ & 0.008 \\
\hline \multirow{2}{*}{ Dominant } & $\mathrm{A} / \mathrm{A}$ & 247 & 50.7 & 56 & 41.2 & \multirow{2}{*}{1.46} & \multirow{2}{*}{$0.99,2.16$} & \multirow{2}{*}{0.053} \\
\hline & $\mathrm{A} / \mathrm{C}+\mathrm{C} / \mathrm{C}$ & 240 & 49.3 & 80 & 58.8 & & & \\
\hline \multirow{2}{*}{ Recessive } & $\mathrm{A} / \mathrm{A}+\mathrm{A} / \mathrm{C}$ & 447 & 91.8 & 114 & 83.8 & \multirow{2}{*}{2.16} & \multirow{2}{*}{$1.23,3.8$} & \multirow{2}{*}{0.009} \\
\hline & $\mathrm{C} / \mathrm{C}$ & 40 & 8.2 & 22 & 16.2 & & & \\
\hline \multirow{2}{*}{ Overdominant } & $\mathrm{A} / \mathrm{A}+\mathrm{C} / \mathrm{C}$ & 287 & 58.9 & 78 & 57.4 & \multirow{2}{*}{1.06} & \multirow{2}{*}{$0.72,1.56$} & \multirow{2}{*}{0.766} \\
\hline & $\mathrm{A} / \mathrm{C}$ & 200 & 41.1 & 58 & 42.6 & & & \\
\hline \multirow{3}{*}{ Codominant } & $\mathrm{A} / \mathrm{A}$ & 247 & 50.7 & 56 & 41.2 & 1 & - & \multirow{3}{*}{0.018} \\
\hline & $\mathrm{A} / \mathrm{C}$ & 200 & 41.1 & 58 & 42.6 & 1.27 & $0.84,1.92$ & \\
\hline & $\mathrm{C} / \mathrm{C}$ & 40 & 8.2 & 22 & 16.2 & 2.43 & $1.33,4.42$ & \\
\hline
\end{tabular}

a Number of $\mathrm{C}$ allele in the genotype 
Table 4. Cox multivariable survival analysis of the rs12608932_UNC13A*

\begin{tabular}{llllll} 
Genetic model & Factor & HR & $\mathbf{9 5 \%}$ CI & p-value & p-value model \\
\hline Dominant & sex & 1.067 & $1.672,0.681$ & 0.777 & \\
& Age at onset & 0.955 & $0.974,0.936$ & $\mathbf{0 . 0 0 0 1}$ & $\mathbf{0 . 0 0 0 1}$ \\
& topo & 0.802 & $1.247,0.516$ & 0.328 & \\
& UNC13A_C+ & 0.585 & $0.936,0.366$ & 0.025 & \\
\hline Recessive & sex & 0.957 & $1.493,0.614$ & 0.848 & \\
& Age at onset & 0.958 & $0.977,0.939$ & $\mathbf{0 . 0 0 0 1}$ & $\mathbf{0 . 0 0 0 1}$ \\
& topo & 0.755 & $1.200,0.475$ & 0.234 & \\
& UNC13A_CC & 1.439 & $1.873,1.105$ & $\mathbf{0 . 0 0 7}$ & \\
& sex & 1.088 & $1.698,0.696$ & 0.712 & \\
& Age at onset & 0.951 & $0.971,0.932$ & $\mathbf{0 . 0 0 0 1}$ & $\mathbf{0 . 0 0 0 1}$ \\
& topo & 0.744 & $1.151,0.481$ & 0.784 &
\end{tabular}

${ }^{*}$ Calculated for deceased and equivalent $(\mathrm{n}=80)$ and for different genetic models (adjusted by sex and age at onset and initial topography) 
Table 5. Effect of the rs12608932_UNC13A variant on the ALSFRS-R scale calculated for different genetic models (adjusted by sex, age at onset and topography)

\begin{tabular}{llcccccc} 
Genetic model & genotype & $\mathbf{n}$ & mean & se & Diff. & $\mathbf{9 5 \%}$ CI & p-value \\
\hline Dominant & $\mathrm{A} / \mathrm{A}$ & 55 & 3.109 & 0.118 & 0 & & \\
& $\mathrm{~A} / \mathrm{C}-\mathrm{C} / \mathrm{C}$ & 80 & 2.661 & 0.116 & -0.431 & $-0.747,-0.115$ & $\mathbf{0 . 0 0 8}$ \\
\hline Overdominant & $\mathrm{A} / \mathrm{A}-\mathrm{C} / \mathrm{C}$ & 77 & 3.056 & 0.094 & 0 & & \\
& $\mathrm{~A} / \mathrm{C}$ & 58 & 2.562 & 0.149 & -0.460 & $-0.770,-0.149$ & $\mathbf{0 . 0 0 4}$ \\
\hline Codominant & $\mathrm{A} / \mathrm{A}$ & 55 & 3.109 & 0.118 & 0 & & \\
& $\mathrm{~A} / \mathrm{C}$ & 58 & 2.562 & 0.149 & -0.519 & $-0.857,-0.181$ & 0.012 \\
& $\mathrm{C} / \mathrm{C}$ & 22 & 2.923 & 0.143 & -0.201 & $-0.651,0.248$ & \\
\hline
\end{tabular}

